\title{
Crença, descrença, conversão
}

\author{
Danilo Marcondes \\ PUC-Rio/UFF
}

\section{RESUMO}

Embora a noção de crença e sua relação com a ação sejam bastante discutidas na literatura sobre o ceticismo, a descrença e as mudanças de crenças são pouco examinadas, apesar de bastante relevantes para a análise das crenças. Em que condiçốes mudamos de crenças, abandonamos crenças anteriores e adotamos novas crenças? Examinaremos dois exemplos significativos e muito influentes na tradição que podem nos esclarecer quanto a isso: Agostinho e Martinho Lutero.

\section{PALAVRAS-CHAVE}

Crença; Descrença; Conversão; Ceticismo.

\section{ABSTRACT}

The discussion of belief formation and of the relation between action and belief is amply considered in the literature on skepticism. Situations in which we change our beliefs, or simply adopt a posture of disbelief have not been adequately considered, although relevant for the analysis of belief. In what circumstances do we change our beliefs or adopt a posture of disbelief? I propose to discuss two cases which might clarify us regarding these questions: Saint Augustine and Martin Luther.

\section{KEY WORDS}

Belief; Disbelief; Conversion; Skepticism. 
A Oswaldo Porchat, in memoriam

\section{Introdução: sobre as crenças}

Uma das questôes centrais do debate em torno do ceticismo consiste na discussão sobre a natureza das crenças, seu processo de formação e seu papel na experiência humana. Proponho traduzir doxa por crença e não por opinião. "Crença” parece ter mais claramente uma acepção epistêmica assim como religiosa. Podemos falar de crenças científicas e de crenças religiosas, mas usualmente não falamos de opiniōes científicas ou religiosas. "Opinião" parece ter um caráter mais geral e estar mais ligada ao senso comum do que "crença". Além disso, "crença" tem seus opostos óbvios particularmente relevantes para nós como "descrença" ou "incredulidade", o que não parece ocorrer com "opiniáo", embora alguém possa dizer não ter uma opinião sobre algo, não ter uma crença sobre algo parece menos plausível, ou menos usual. Podemos pedir uma "segunda opinião" médica, em que opinião é sinônimo de parecer ou diagnóstico, mas não pedimos uma segunda crença. Isso mostra que "opinião" e "crença" não são intercambiáveis e que "crença" traduz melhor doxa do ponto de vista de questóes epistêmicas e religiosas que examinaremos a seguir.

Pode-se dizer que discussões sobre a diaphonia, a aporia e a époche, também conceitos centrais da filosofia cética, pressupóem como são entendidas as crenças. Mas, o que são crenças? Essa questão perpassa as Hipotiposes Pirrônicas (I) de Sexto Empírico (1976) e é um dos temas centrais dos Academica (1979). No contexto contemporâneo temos algumas contribuiçóes já clássicas para essa discussão sobretudo as de Barnes, Burnyeat e Frede incluídas na coletânea The Original Skeptics (1997). Proponho discutir aqui uma questáo anterior à de saber se o cético pode viver sem crenças, o que no meu entender depende de como crenças são entendidas. Proponho também considerar um aspecto menos examinado, o processo de mudança e abandono de crenças, assim como a questão sobre o que nos leva a adotar novas crenças, a conversão. Há, portanto, uma dinâmica de crenças que pode nos esclarecer sobre esta noção e seu papel no pensamento cético.

A literatura especializada tem se dedicado mais às bases das crenças ou a seu estabelecimento do que aos casos de mudanças de crenças. Dois exemplos representativos são C.S. Peirce (I877), "The fixation of belief” e L. Wittgenstein (1974), On certainty. No que consiste exatamente esse processo? É claro que se pode abandonar uma crença sem necessariamente substituí-la por outra. Seria o caso do crente que se torna pura e simplesmente ateu, ou descrente, sem adotar outra religiáo. Crenças são excludentes, não se pode ter diferentes crenças sobre algo ao mesmo tempo, mas, 
por outro lado, adotar uma crença não é incompatível com aceitar que outras pessoas tenham outras crenças, o que caracteriza casos de tolerância e de visão pluralista.

Para isso pretendo analisar a contingência das crenças e as circunstâncias ou situaçóes em que mudamos de crenças ou as abandonamos. $\mathrm{O}$ que nos leva a isso? A questão, portanto, consiste não propriamente no que nos faz adotar certas crenças, ou a aceitá-las, mas ao contrário, o que nos faz mudar de crenças.

A Antiguidade Tardia nos dá alguns exemplos disso, sendo a conversão de Agostinho um caso privilegiado. Ele próprio examina essa questão ao longo das Confissóes (20I7, sobretudo, cap. 5), porque se refere diretamente ao papel do ceticismo nesse processo. Agostinho, por sua vez, influenciou fortemente nesse aspecto o primeiro momento da Modernidade. Encontramos nos séculos XVI e XVII um período significativo para essa discussão dados os conflitos religiosos, políticos e científicos que influenciaram conversôes, mudanças de crenças, e a questão sobre a tolerância enquanto convivência entre diferentes crenças no que Popkin (2000, cap. I) denominou “a crise intelectual da Reforma”, quando se dá uma mudança radical no pensamento. Nesse período, crenças são contrastadas com convicções fortes (dogmas) e as questóes do erro (falsas crenças), da consciência errônea, da incerteza e da falibilidade emergem como problemas centrais para a filosofia colocando em xeque as teorias tradicionais. Um grande exemplo nesse contexto foi a Revolução Científica em suas várias etapas.

\section{Dianoia e doxa}

A noção de crença (doxa) é uma das mais centrais da filosofia grega antiga e de importância capital para o ceticismo. Podemos tomar como ponto de partida para a nossa análise o Teeteto de Platão, locus classicus sobre a discussão da relação entre doxa e episteme.

A seguinte passagem (I89e-I90a) desse diálogo me parece especialmente relevante para o exame da formação das crenças através de um exercício de pensamento (dianoia). Quando cotejamos as principais traduçóes dessa passagem observamos uma grande variação terminológica. Apresento aqui uma tradução que, comparando boa parte dessas existentes, leva em conta as questóes centrais que pretendo discutir. $\mathrm{Na}$ passagem considerada, Teeteto pergunta a Sócrates o que este entende por pensamento (dianoia) e Sócrates, sempre avesso a definiçóes percebe que precisa responder, caso contrário a discussão entre ambos correria o risco simplesmente de não prosseguir. Diz então que o pensamento é:

Um discurso (logos) que a alma (psyché) mantém consigo mesma (pros autén), acerca do que quer examinar. Como ignorante que sou lhe dou essa explicação. Mas, é assim que imagino a alma no ato de pensar: formula uma espécie 
de diálogo consigo mesma com perguntas (erotosa) e respostas, ora para afirmar, ora para negar. Quando chega a uma decisão, seja avançando mais devagar seja um pouco mais depressa e se fixa em algo sem hesitação (me distáze): eis o que denominamos crença (doxa). Digo, pois, que formar uma crença é discursar (legein), um discurso (logos) enunciado, não evidentemente de viva voz para outrem, porém em silêncio, consigo mesmo (pròs autón).

Os mais conhecidos comentadores do Teeteto, e refiro-me a Cornford (1979), Burnyeat (1999) e McDowell (1990), não nos ajudam muito no caso de meu interesse específico. Suas interpretaçôes são muito próximas e a questão central a que se referem, por exemplo, no breve comentário de Cornford (I979, p. II8), diz respeito à distinção entre o juízo verdadeiro e o falso, que antecede essa passagem, embora aqui as noçôes de verdadeiro e falso não estejam presentes, nem a distinção seja feita. McDowell e Burnyeat seguem a mesma linha, concentrando-se na mesma questão sobre o juízo e a natureza proposicional do pensamento (dianoia) (Burnyeat, 1999, p. 84-85). Katja Vogt (2012, p. 84), que sigo mais de perto, levanta a questâo sobre a tradução de doxa como juízo, admitindo que talvez "crença" seja preferível e indica que McDowell admite (1999, p. 193) as duas possibilidades, embora se incline por juízo, tendo em vista o contexto mais amplo a que a passagem pertence. Certamente esses comentários refletem os interesses de uma leitura por filósofos analíticos.

Minha proposta, contudo, consiste em me concentrar em doxa interpretada como crença e examinar a passagem acima como apresentando uma análise do processo de formação de crenças em um sentido bastante específico.

Sobretudo nos diálogos socráticos, um dos objetivos fundamentais de Sócrates com sua dialética argumentativa consiste em expor as inconsistências das crenças comuns, as não-examinadas, revelando sua fragilidade e fazendo com que seu interlocutor reconheça sua própria ignorância, sua falta de entendimento do que lhe parecia antes claro, abrindo assim caminho para a mudança dessa crença, mas apenas abrindo caminho, sem nenhuma garantia de que essa mudança virá. Segundo Sócrates, fazer alguém mudar de crença é uma das coisas mais difíceis de conseguir, já que as pessoas costumam se aferrar a suas crenças e resistir aos argumentos contrários a elas. Por vezes a tradução de dogma por "opiniáo" capta o que poderíamos chamar exatamente de um sentido dogmático de opiniáo: em inglês temos mesmo o adjetivo "opinionated" com esse sentido (Cícero, I979, usa o termo opinator). Mas, Sócrates não pretende apenas a mudança de crença, ou a substituição de uma crença por outra, mas a mudança de atitude, de uma atitude dogmática no sentido de não-refletida, para uma atitude crítica ou filosófica caracterizada pelo autoexame e pela formulação da crença apenas após a satisfação de certas condições, como o texto acima deixa claro, embora não diga exatamente quais. 
O Teeteto é considerado (v. Barnes, I997, p. 68-69) como o diálogo por excelência em que Platáo introduz o termo dogma em um sentido filosófico se referindo inicialmente às crenças de Teeteto (I57, seção sobre a maiêutica) a serem examinadas. Em seguida, na discussão acerca de Protágoras, dogmata são as crenças derivadas das sensações, sendo praticamente sinônimas de apreensões sensíveis. A passagem em questão pertence ao momento no texto em que Sócrates está argumentando em defesa da necessidade de que se considere a crença verdadeira (alethés doxa) e distinga a verdadeira da falsa (ou errônea, ou confusa).

Vejamos o texto. O ponto de partida, "aquilo que se quer examinar", pode ser interpretado como sképsis e zétesis, a investigação e a busca, embora esses termos não sejam empregados aí, pois seu uso cético é muito posterior. O "discurso que a alma mantém consigo mesma" é com frequência interpretado como "discurso interior" (Vogt, se refere a "inner", 20I2, p. 85), embora essa já me pareça uma leitura excessivamente moderna. Sem discordar inteiramente, sugiro interpretá-lo como "reflexivo", aquele em que alguém toma a si mesmo como interlocutor como em um diálogo, ou melhor, em um monólogo ou um solilóquio, quando me dirijo a mim mesmo. Como, aliás, é dito em seguida. Esse processo consiste em formular perguntas e respostas, afirmando e negando, ou seja, consiste em examinar diferentes possibilidades e alternativas. Entendo aí o processo no qual ocorre segundo os céticos a diaphonia, o conflito entre as várias possibilidades. Finalmente quando não tem mais nenhuma hesitação (distaze, traduzido por vezes por dúvida), o indivíduo toma então uma decisão (traduzido por vezes por formula um juízo). Esse é o passo crucial para a formulação de uma crença. É o passo que o cético que permanece na époche não chega a dar porque não encontra critérios que o permitam tomar essa decisão, não supera a hesitaçáo e permanece na aporia, o impasse diante de alternativas possíveis. O cético (Cícero, Academica, II, 24, diz, o “sábio", sapiens) é, portanto, aquele que em relação a um determinado assunto não se sente satisfeito, não toma uma decisão e não forma uma crença. Isso se dá, como parece claro, em relação a uma crença pontual, "aquilo que se quer examinar". O processo pode ser retomado na medida em que esse diálogo da alma consigo mesma pode continuar. E, não satisfeito, o pensamento pode mudar, a decisão pode ser revista, se diante das perguntas e respostas que a alma formula outros fatores, elementos, evidências, etc. forem apresentados. Sócrates náo detalha o que faz com que aquele que realiza esse exame tome a decisão. Nem detalhará isso ao longo do diálogo na medida em que este é um diálogo aporético e a solução apresentada ao final, o logos, ou melhor, aitías logismos é ela própria problemática, sujeita à circularidade e ao regresso ao infinito.

Platão parece se referir a um processo reflexivo, que pode ser longo ou breve, e não a crenças dogmáticas adotadas sem interrogação, que são aquelas que Sócrates coloca 
em questão no exercício de sua dialética nos primeiros diálogos. A reflexão filosófica envolve, portanto, a possibilidade de mudar as crenças, revê-las, reformulá-las ou, simplesmente, não formar uma crença como resultado da deliberação. Podemos ver nessa descrição o que seria a "vida examinada" a que Sócrates se refere na Apologia. Crenças no processo descrito nessa passagem não são dogmáticas no sentido de crenças entrincheiradas e resistentes a mudanças, mas, ao contrário, são sujeitas a mudança como resultado desse reexame. Observe-se que não há nessa passagem nenhuma referência à verdade. Apenas a um momento quando não há mais motivo para hesitação, mas não necessariamente em caráter definitivo, porque o diálogo pode ser retomado. As crenças dizem respeito a determinados assuntos que são examinados.

Tampouco há uma referência explícita a algum termo que se possa interpretar como interioridade, tudo que é dito é "em silêncio" (allà sige), ou seja, não é exprimido verbalmente, embora algumas traduçóes cheguem a falar em discurso interior, como dissemos anteriormente.

Náo se trata nesse caso da passagem de crenças para conhecimento (episteme), o que será discutido ao longo do Teeteto, mas de crenças não-examinadas para crenças examinadas, que então dão origem a um logos.

Proponho que essa passagem do Teeteto nos fornece um modelo para a interpretação da formação de crenças e mesmo para a mudança de crenças. Apresentaremos em seguida alguns momentos privilegiados que ilustram essa hipótese.

A discussão nos Academica pode ser útil a esse respeito, já que, segundo Cícero, essa parece ser a posição de Arcesilau em seu confronto com os estoicos, compatível com a descrição socrática do processo acima, porém, adotando a époche ao não encontrar elementos suficientes para formar uma crença e proferir um juízo. Segundo Arcesilau, isso não só é possível, mas esse é mesmo o dever do sábio (Academica, II, 24). Exemplo disso temos na falácia do sorites (Ac. II, 49, 94). Nesse caso, Crisipo, quando interrogado passo a passo (gradatim interrogetur, como no processo descrito no Teeteto), e sem encontrar uma posiçáo convincente (portanto incapaz de formar uma crença), deve permanecer como que em repouso (perveniat quiescere), ou deve até mesmo, como é dito, hesychazein, ou seja, descansar. Em resposta, Crisipo acrescenta de forma irônica, "pode adormecer e até roncar", porque no caso do sorites a questão pode ser sempre retomada, sendo inconclusiva (Academica, II, 29).

O modelo de pensamento descrito é compatível com diferentes pessoas passando por esse mesmo processo chegando a conclusóes diferentes porque farão esse exame recorrendo a outras crenças, alguma delas não examinadas, ou a evidências sensíveis entendidas de maneiras diferentes. Além disso, a mesma pessoa pode reexaminar algo que procura e rever suas crenças anteriores diante de novas e diferentes evidências sensíveis ou de outras crenças. $\mathrm{O}$ processo é constante, caso contrário 
produziria crenças dogmáticas, cristalizadas, entrincheiradas e não seria mais retomado, deixando, portanto, de se pensar nesse sentido filosófico.

Segundo o que propomos como a interpretação cética dessa passagem, o sábio mantém sua liberdade e preserva sua capacidade de julgar ao não se sentir compelido a sustentar uma posição determinada, ou seja, uma doutrina $(A c . \mathrm{I}, 2,8)$. A indeterminação do pensamento seria assim uma manifestaçáo da própria liberdade de pensar e de não tomar uma decisão quando não houver base para isso. Por outro lado, pode parecer surpreendente que aqueles que mudam de crenças raramente apresentem justificativas explícitas. Vamos procurar encontrar alguns exemplos disso.

\section{Dois casos de mudanças radicais de crenças: Agostinho e Lutero}

Proponho darmos agora um salto e tomarmos brevemente a conversão de Agostinho como exemplo, até porque ele se refere por duas vezes (Confissóes, 2017, [c. 397-400], V, I8-I9, 25) aos Acadêmicos. Discípulo dos Maniqueus por cerca de oito anos, Agostinho descreve a crise pela qual passa ao se sentir em suas próprias palavras em conflito consigo mesmo (X, I8), em um processo autorreflexivo semelhante ao descrito na passagem do Teeteto acima. Em seguida (I9) diz que esses pensamentos surgiram devido aos filósofos "chamados Acadêmicos", mais sábios que os demais por manter que os homens devem duvidar de tudo (quos Academicos appellant, quod de omnibus dubitandum esse) e que nenhuma verdade pode ser compreendida pelos homens, contrastando essa posiçáo com o dogmatismo dos Maniqueus. E conclui, "à maneira dos Acadêmicos, como se supóe, duvidando de tudo e flutuando entre todos (inter omnia fluctuans), decidi que os Maniqueus deveriam ser abandonados, considerando que mesmo enquanto duvidava, náo deveria continuar naquela seita" (itaque Academicorum more, sicut existamantur, dubitans de omnibus atque inter omnia fluctuans, Manichaeos quidem relinquendos esse decrevi; non arbitrans eo ipso tempore dubitationis meae in illa secta mihi permanendum esse).

Recorrendo ao Teeteto, podemos entender Agostinho descrevendo o momento de hesitação enquanto examina várias correntes filosóficas e argumentos (inter omnia fluctuans) e decidindo, de início, que não permanecerá no Maniqueísmo mesmo ainda antes de decidir-se pelo Cristianismo. Chamo a atenção para o flutuando (fluctuans), ou seja, para um momento de indefinição. É o Cristianismo que fornecerá o critério definitivo de decisão, supra filosófico, supra cognitivo mesmo, a fé, como nos mostra a conclusão de Contra acadêmicos (contemporâneo das Confissóes), em que esse processo é descrito em detalhe. Agostinho usa os acadêmicos contra os Maniqueus e finalmente o Cristianismo contra os acadêmicos. O processo de con- 
versão envolve um exame racional das seitas e filosofias, os argumentos dos acadêmicos fazem com que rejeite o dogmatismo maniqueu, mas é o salto da fé que o coloca no caminho do Cristianismo. O De magistro (388-39I) introduz a noção de interioridade, uma concepçáo de mente como um espaço interior, mostrando que é o Cristo que está em nós que nos permite o entendimento, uma versão neoplatônica cristã do inatismo do Ménon: a luz natural, na expressão de Agostinho, uma centelha da mente divina na mente humana. O pensamento tem agora uma âncora que pode fazer cessar o processo de autoexame, produzindo uma certeza definitiva. O fideísmo, retomado na modernidade tem suas bases nessa concepção, segundo a qual esgotada a razão e sendo impossível decidir entre posiçóes opostas por falta de critério, emerge o caminho da fé como superação não argumentativa das controvérsias, como um critério não cognitivo.

Um novo salto nos leva à modernidade e ao que Popkin (2000) chamou de "crise intelectual da Reforma" da qual Agostinho não está tão distante, dada a sua influência no pensamento filosófico e teológico deste período. Proponho agora uma leitura de uma passagem de Lutero ilustrativa dessas questóes que vimos discutindo na Modernidade.

Trata-se do famoso texto de conclusáo de seu discurso perante a Dieta de Worms, proferido em alemão e em seguida em latim (I8 de abril de I52I). Essa assembleia de bispos e príncipes alemães, que marca a ruptura de Lutero com a Igreja, foi precedida por várias controvérsias teológicas, exegéticas e em última análise políticas entre seguidores de Lutero e defensores da Igreja. Ameaçado nesse momento de excomunhão por heresia Lutero afirma ter considerado e pesado as consequências do que tem mantido. É exigido dele que se retrate. E, de acordo com nossa análise, retratar-se é um processo de voltar atrás em suas crenças, reexaminá-las e aceitar seu erro, tomando uma nova decisão, fazendo outra escolha. Interrogado, Lutero profere um discurso cuja célebre conclusão se segue:

Vossa Majestade Imperial e vossas excelências exigem uma resposta simples. Aqui está ela simples e sem adornos. A menos que eu seja convencido de estar errado pelo testemunho das Escrituras, pois não confio na autoridade sem sustentaçâo do papa e dos concílios, uma vez que é óbvio que em muitas ocasióes erraram e se contradisseram, ou por um raciocino manifesto eu seja condenado pelas Escrituras a que faço meu apelo e minha consciência se torne cativa da palavra de Deus, eu não posso retratar-me e não me retratarei acerca de nada, já que agir contra a própria consciência não é seguro para nós, nem depende de nós. Isso é o que sustento. Não posso fazê-lo de outra forma. Que Deus me ajude. Amém. (Lutero, 1999, p. 223-224).

Em sua ruptura decisiva com a Igreja Lutero evoca dois argumentos. O primeiro consiste em mostrar a falta de credibilidade da Igreja ao levarmos em conta a sua 
história. Nem os concílios, nem os papas merecem ter suas autoridades reconhecidas porque com frequência erraram e se contradisseram. Trata-se, portanto, de uma história de conflitos doutrinários sem critério de decisão, de uma longa diaphonia, pode-se dizer. Por exemplo, durante o grande cisma do séc. XV o teólogo francês Jean Gerson afirmara aceitar a autoridade do papa, mas simplesmente diante dos três papas em disputa não tinha como decidir qual deles seria o legítimo. Recusando a autoridade institucional, a autoridade externa, pode-se dizer, Lutero recorre à sua consciência como nova autoridade, a autoridade interna, que depende apenas dele, de sua natureza humana. É essa luz interior, herdeira da tradição agostiniana, que dá início à noção moderna de consciência que permite o contraste entre o indivíduo e o mundo das instituiçôes: a Igreja e o Império. O que faz com que a autoridade de um indivíduo possa se contrapor à Igreja, aos bispos, aos concílios, ao Imperador, à toda tradição histórica? $\mathrm{O}$ que faz com que a consciência individual seja o lugar da certeza? A única fonte de autoridade são as Escrituras, interpretadas à luz da fé. Feito o exame e superada qualquer hesitação, Lutero não tem dúvidas e assume uma fé dogmática, "agir contra a própria consciência não é seguro", "nem depende de nós", ou seja, uma vez que isso fique claro não temos nem como, nem porque voltar atrás. $\mathrm{O}$ autoexame funciona como um processo pelo qual conseguimos eliminar as falsas crenças herdadas da tradição, abrindo caminho por sua vez à fonte da nova crença inquestionável, que se encontra na própria natureza humana e que torna o ser humano capaz da experiência da fé através da revelação da palavra de Deus, as Escrituras, o que nos compele a crer. Não se trata apenas de uma decisão, mas de uma força que efetivamente nos compele. Lutero aplica assim a solução agostiniana ao final de Contra Acadêmicos, o critério da fé.

Em sua polêmica com Lutero, Erasmo de Rotterdam (2006), representando a posição humanística por excelência, levanta um argumento cético: diante de dois indivíduos que fazem leituras divergentes das Escrituras, já que o texto sagrado não é autoevidente, como decidir qual está correto? Lutero responde que se trata daquele que tem a fé simples e sincera, inspirada pelo Espírito Santo. Fornece, portanto, um critério na linha da teologia agostiniana. Erasmo reitera a pergunta: mas como podemos saber qual é este indivíduo? Além disso, como poderia ele saber que antes estava errado, ao seguir a tradição, e que agora está certo? Mostra com isso que o problema cético se repóe mesmo no âmbito da certeza da consciência individual. Ao que Lutero simplesmente responde de forma contundente, "o Espírito Santo não é um cético!”, encerrando o debate (Popkin, 200o). Temos com isso não só uma cisão com a Igreja, mas também com a própria filosofia, não há mais espaço para diálogo, autoexame e formulação de dúvidas ou hesitações. 
As convicções religiosas são crenças resistentes a mudanças com base em uma autoridade externa. Lutero descreve a ruptura com uma autoridade institucional, a Igreja, externa, portanto, recorrendo a uma autoridade interna, sua consciência com

base nos critérios que vimos acima. É possível mudarmos de crenças mantendo o dogmatismo inicial, a mesma forma com outro conteúdo. É possível também que quando pelo autoexame, fica clara a possibilidade de rever crenças, que isso abra o caminho para a revisão das crenças, e, portanto, para uma relativização de sua força, do que nos compele a crer. O que nos compelia antes, não nos compele mais, é o compelir, característico do dogmatismo que se enfraquece.

\section{Pode o cético ter crenças?}

Para retomarmos a questão tradicional: Pode o cético ter crenças? No sentido em que vimos não só pode ter crenças como efetivamente pode mudar de crenças, uma das características do antidogmatismo, na medida em que muda o contexto e muda o que o compele a crer. A questão da mudança de crenças e sua relação específica com a questão religiosa são características centrais da modernidade e da influência difusa do ceticismo nesse período.

Os chamados "contextos de transiçáo" em que um sistema de crenças muda são representativos dessa questáo. $\mathrm{O}$ caso da Reforma Protestante é significativo de um momento histórico em que o que antes era considerado válido deixa de sê-lo e passa a ser substituído por outro sistema.

Nas Investigaçôes Filosóficas, Wittgenstein (\$23) nos diz exatamente que alguns jogos de linguagem deixam de existir e outros surgem. Isso se dá no contexto de formas de vida, o pano de fundo em que crenças se constituem. Mas novos jogos de linguagem podem conviver com os antigos sem que um exclua o outro, caso da Reforma e do Catolicismo. Wittgenstein insiste também, e esse é um argumento frequente, que dúvidas só podem surgir a partir de certezas, ou crenças básicas, que constituem seu pano de fundo. Em Sobre a certeza $(\$ 358)$, Wittgenstein relaciona certezas com formas de vida, mas, como vimos, formas de vida mudam e nesse sentido também mudam sistemas de crenças que pertencem a essas formas de vida.

Crenças básicas são crenças náo-examinadas, ou seja, pressupostos que náo passaram pelo processo descrito por Sócrates no Teeteto, na passagem que examinamos acima. Podemos distinguir assim dúvidas que surgem dentro de um sistema de crenças e que simplesmente consistem em correlacionarmos as crenças dentro desse sistema de modo diferentes, isto é encontrar novas evidências, redefinir novos conceitos; ou dúvidas que levam à necessidade de mudar todo um sistema de crenças, quando por exemplo, abandonamos crenças religiosas e passamos a assumir o 
ateísmo ou agnosticismo, em que não nos vemos mais pertencendo a uma determinada forma de vida. Situações que são discutidas pelo assim chamado Direito Transicional são exemplos disso: leis de anistia tornam condenaçôes nulas, ou deixam de considerar crime o que anteriormente era assim considerado. Diferentes sistemas de crença podem conviver em certos contextos, por exemplo, entre católicos e protestantes no contexto do século XVI e a luta pela tolerância consistiu em defender que essas crenças pudessem ser mutuamente reconhecidas e que ambas as correntes religiosas tivessem liberdade de culto. A possibilidade de aceitar crenças alternativas, não significa que devamos aderir a elas.

Vimos no exame dos textos do Teeteto, de Agostinho e de Lutero, que crenças podem ser examinadas, reexaminadas, submetidas a questionamento e eventualmente revistas e novas crenças adotadas. Isso pode ser feito através de um exame de crenças específicas, como no caso do Teeteto que descreve o processo pelo qual formamos crenças examinadas, o que é claro, como o diálogo mostrará, não garante a verdade dessas crenças, mas que é diferente das mudanças de crenças que encontramos em Agostinho e em Lutero, em que um sistema de crenças é questionado, o Maniqueísmo no caso de Agostinho, o Catolicismo no caso de Lutero e outro sistema constituído ou adotado. Crenças náo existem isoladamente e mesmo quando examinamos crenças específicas, examinamos os aspectos a favor e contra como mostra a passagem do Teeteto e esses aspectos pertencem a formas de vida. Vimos também, a partir das consideraçôes de Wittgenstein que formas de vida elas próprias não são imutáveis. Portanto, situaçóes de conflitos entre crenças, ou entre sistemas de crenças, são relevantes para essa análise. Vimos que há mudanças ou revisóes de crenças mantendo-se o próprio sistema de crenças, o conjunto de crenças que se articulam formando o pano de fundo em que cada crença pode ser examinada, mas vimos também situaçóes mais radicais em que todo um sistema de crenças pode desmoronar dando origem a um novo sistema que sustentará novas crenças, caso da Reforma Protestante.

Retomando a questáo clássica: pode o cético viver sem crença? Segundo a análise que propusemos inclusive de termos como "descrença", certamente pode. Náo pode viver sem algum sistema de crenças que constitui o pano de fundo e o conjunto de pressupostos de sua açáo e a forma de vida em que sua experiência se desenvolve. Mas, dentro desse sistema, as crenças podem ser examinadas e revistas na linha do que encontramos na passagem do Teeteto analisada acima. Não há pressupostos que não possam ser discutidos. Além disso, sistemas de crença, religiosos, políticos e científicos, podem desmoronar como ocorreu no início da Modernidade, sendo eventualmente substituídos em parte ou totalmente por novos sistemas de crenças. A discussão 
cética contribui, como contribuiu nesse caso histórico, para essas mudanças, revelando assim a contingência dessas crenças e dos próprios sistemas, indicando a possibilidade de alternativas e a necessidade de posturas náo-dogmáticas diante de crenças.

Crenças devem ser consideradas como relativas, mas devemos entender isso como relatividade sem relativismo. O relativismo constitui uma limitação para a filosofia se houver pulverização das correntes filosóficas sem discussão entre elas e sem o conflito argumentativo que, para os céticos, caracteriza por excelência a atividade filosófica, levando as correntes filosóficas a se fecharem em si mesmas. Corremos o risco de cair assim em uma tolerância que pode significar desinteresse pelas outras correntes, na assim chamada "dócil indiferença", como diria Freud. O ceticismo significa a possibilidade de preservar o debate filosófico essencial.

\section{Bibliografia}

Agostinho (2017). Confissóes. Tradução de Maria Luiza Amarante. São Paulo: Paulus. Agostinho (2008). Contra acadêmicos. Tradução de Frei Agustino Belmonte. São Paulo: Paulus. Barnes, J. (1997). “The beliefs of a pyrrhonist”, in The Cambridge Classical Journal. Burnyeat e Frede (ed). Bolzani, R. (2013). Acadêmicos versus Pirrônicos. São Paulo: Alameda.

Burnyeat, M. (1990). The Thaetetus of Plato. Indianapolis: Hackett.

Burnyeat, M. e M. Frede (orgs.) (1997). The original skeptics. Indianapolis \& Cambridge: Hackett. Cicero (1979). Academica. Cambridge: Harvard University Press.

Cornford, F. (1979). Plato's theory of knowledge. London: Routledge \& Kegan Paul.

Erasmus \& Lutero (2006). Discourse on free will. London \& New York: Continuum.

Febrve, 1. (2003). Le problème de l'incroyance au XVIe siècle. Paris: Albin Michel.

Giocanti, S. (200I). Penser l'irrésolution. Honoré Champion: Paris.

Lutero (1999). “The Diet of Worms, I52I. Luther's Final Answer”, in: Documents of de Christian Church, Oxford: Oxford University Press.

Marcondes, D. (2016). Textos básicos de história e filosofia das ciências. Zahar: Rio.

McDowell, J. (1999). Plato's Thaetetus, commentary and translation. Oxford: Clarendon Press.

Peirce, C. S. (I877). "The fixation of belief". In Popular Science Monthly, I2. p. I-I5. http://www.peirce.org/writings/pio7.html

Popkin, R. (200o). História do ceticismo de Erasmo a Spinoza. Tradução de Danilo Marcondes Filho. Rio de Janeiro: Francisco Alves.

Sextus Empiricus (1976). Pyrrhonian Hipotiposes. Cambridge: Harvard University Press.

Wittgenstein, L. (2009). Philosophical investigations. Oxford: Wiley-Blackwell.

Wittgenstein, L. (1974). On certainty. Oxford: Blackwell.

Vogt, K. M. (2012). Belief and truth: a skeptic reading of Plato. Oxford: Oxford University Press. 